\title{
Geo-Demographic Market Segmentation: \\ an Application In Marketing Management
}

\section{Dan Rutledge}

\author{
Thomas Callahan \\ University of Michigan-Dearborn \\ Dearborn, Michigan
}

\section{Introduction}

Segmentation has been a key tenant of marketing since its introduction by Smith in 1956 ([2], [6]). This concept is based on the premise that differences in response behaviors exist among various groups of buyers comprising the market. For segmentation to be an effective analytical tool customers within a segment must display homogenous behavior while between segments customers must display heterogenous behaviors.

The purpose of this paper is to illustrate the value and an application of geo-demographic market segmentation in practice. It can be shown that this method is easily implemented, has the potential for uncovering valuable information, and can be easily conducted for a minimal cost. More important, managers can then make decisions based upon concrete information rather the relying on assumptions based upon overall market 'averages'.

Within this context, a market research study was conducted for a small retailer of women's clothing. Specifically, this sponsor wanted to know if there was a difference between the two cities that bordered the shopping center containing their store (these cities are referred to later as City $\mathbf{A}$ and City B). If differences were found this might explain why store sales were disappointingly low. In the process of analyzing the data, a third area (City C) emerged as important because its residents accounted for a large proportion of visitors to this center (a surprising fact previously unknown to the sponsor). Thus, the analysis was extended to include City $\mathrm{C}$ in addition to the other two cities originally designated by the sponsor.

The article is divided into six parts. Segmentation theory and its practice in marketing is reviewed; the background of the sponsor's study is outlined; the purpose of the study and related hypotheses are discussed; research methodology and limitations are explained; results and hypotheses are analyzed; and lastly, conclusions and managerial implications are presented.

\section{Segmentation Theory}

Segmentation theory assumes that groups of customers in a market are different on some important dimension(s) that effects their buying behavior. The term 'different' means some unique characteristic that distinguishes one group's behavior from all other groups. Segmentation is possible if significant customer differences are evident. This 
idea contrasts with the assumption that customers are basically alike and can be depicted by some average numerical value.

Three advantages are realized from segmenting a market. The first is an enhanced ability to define the market resulting from discovering important differences among customer groups. Second, these differences serve as a basis for selecting target customer segments. And third, strategies can be developed that should be more effective when competing in these segments.

Absent distinct market differences, a "mass" marketing strategy would be aimed at all customers. Whereas this approach might be adequate for some situations, it is unlikely to produce optimal results. The reason for this is straightforward: those factors differentially significant to individual segments are not emphasized relative to their importance to those respective segments.

Deciding on a basis for segmentation is a central issue in marketing strategy. Which dimension(s) to select depends mainly on management objectives and information requirements. No single segmentation schemata is preferred but several approaches might be appropriate for a given situation [11].

Major segmentation categories most often cited by marketing writers are provided below ([4], [13], [15]). Within each category a variety of delineating dimensions are possible as the following examples show:

Geographic - locations (e.g.) state, MSA, Mid-west

Demographic - descriptors (e.g.) age, occupation, income, gender, education

Psychographic - lifestyle (e.g.) upscale, health-conscious, interests in life

Behavioristic - habits (e.g.) brand loyalty, heavy-user, benefits sought, occasion of purchase

Image - how buyer see themselves in relation to the brands they buy (e.g.) extroverted, blue-collar, sophisticated

One question that arises when deciding on segmentation base is whether to employ an 'a priori' or clustering partitioning method. 'A priori' partitioning is a predetermined method that specifies in advance the basis for segmentation. As a judgmental method it assumes the dimension selected represents a clear and significant difference for defining segments [12].

A shortcoming of ' $a$ priori' partitioning is this method may be too readily assumed a valid basis for segmenting groups. Another is that often this method has not produced sufficiently distinct criteria for differentiating groups [11].

A second partitioning method is cluster analysis. Segments are formed based upon information provided by the respondents themselves, requiring the data to be analyzed before describing the groups. Clustering does not assume automatically significant differences exist or the best basis is already known. However, it is a more complicated and more expansive method to implement in practice.

One basis for ' $a$ priori' partitioning is geo-demographic segmentation, defined as the combination of "geographic units with respect to demographic characteristics 
(e.g., age, gender, income, occupation, etc.) they hold in common" [8]. There are several advantages to employing a geo-demographic approach: it is easy to use, cost effective, relatively inexpensive, and data is available from multiple sources [8]. Geodemographics are widely recognized in practice and are relevant for planning advertising media [1]. They provide a common link among groups (e.g., data base marketing applications) by combining demographics with other household data, improving the marketer's ability to identify and reach target market segments ([11], [18], [19]).

Disadvantages of using geo-demographic dimensions are noted also. Some studies have indicated weak associations between demographics and buying behavior ([3], [7]). Selection of the level of analysis (individual households versus groups of households) has produced different findings [2]. There is a tendency to unconsciously demographically stereotype people [25], the practice of attributing the same behavior to all members of the group (e.g., all women shoppers, age 18-34, rate low price their most important criteria). Geo-demographic variables alone might not be sufficient for describing groups [1]. Data may be aggregated into categories that are too broad [4]. Lastly, the data may be far outdated, and thus, of limited value.

On the other hand, research has been reported supporting the use of demographics for segmentation purposes. Bass, Tigert and Lonsdale [2] found demographics predicted purchasing behavior of grocery products. This study attributed the improved results over previous studies to using household groups rather than the individual household as the unit of analysis. Assael and Roscoe [1] found income level predicted heavy versus light users of long distance calling as well as direct dial versus operator assisted calling behavior.

Blattberg, Buesing, Peacock, and Sen [7] found demographic variables significant for identifying "deal prone" (bargain hunting) behavior among household units. Warren, Stevens, and McConkey [22] combined lifestyle and demographic variables to identify investor segments. This combination explained both investment behavior and type of investment instruments held.

Cannon and Rashid [9] examined the use of demographic selectivity (a proxy for heavy versus light users) for selecting magazines for placing advertising. This method, referred to as indirect matching, requires customers be defined in demographic terms, then matches these profiles with magazines having readers with similar descriptions. In one study of 25 randomly selected products and 50 randomly selected magazines, the authors found a correlation of 0.776 , supporting a relationship between indirect matching efficiency and demographic selectivity.

\section{Background of the Sponsor's Study}

The background for this paper was a market research study conducted for a women's clothing retail chain specializing in mid-priced apparel, appropriate for an office environment, and targeted at an "upscale" clientele. The sponsor had outlets in various suburban shopping centers, all located near a major midwestern city. The central focus of this study was a store located at an established strip-mall shopping center, well known to local residents because of the prominence of its major anchor 
retailer. The trading area covered approximately a six mile radius and contained a population near 250,000 people.

Of the twenty-six businesses at this center, the sponsor's store, the major anchor retailer and four others sold women's clothing. The sponsor's target customers were upscale working women, defined as middle-aged (34-54), white-collar employed (teacher, manager, etc.), with above average incomes $(\$ 41,000)$. Due to this fact only three stores at this center were considered serious competitors.

Initially, the sponsor assumed that because the two cities (A and B) that bordered the center indicated having demographic averages that matched their target customer profile, there would be an attractive customer base within a few miles of their store. They also believed these two cities (combined population 75,000) provided the large proportion of shoppers to this mall.

What was overlooked were the differences between residents of the two cities that indicated distinct market segments. The data also revealed a number of shoppers attracted to the center coming from an area northeast of this location (referred to as City C, area population about 90,000 ) that profiled a somewhat different type of resident. These facts were missed because the assumption was made that the area's overall geo-demographic averages were adequate for explaining this market. For the first three months sales exceeded expectations, but declined thereafter and remained at low levels for the next nine months.

\section{Purpose of the Study and Hypotheses}

The impetus for this study was management's desire to know whether there was evidence of different geo-demographic segments in this trading area, in particular, between City $\mathbf{A}$ and City $\mathbf{B}$. If differences were evident, then shopping behaviors might also differ, leading to varied expectations and evaluations of women's clothing stores as well as the sponsor's store. These factors combined might explain why this store was experiencing problems.

The market research study was to answer four questions. The first question was to determine if City A residents were upscale (matching the sponsor's target customer profile) and different from City B or City $\mathbf{C}$ residents. If different, then City B and City $\mathrm{C}$ might not be providing a sufficient number of upscale customers. Hypothesis 1 relates to the demographic compositions of the residents of the three cities:

H1: The residents of City A have an "upscale" demographic profile compared to residents of City B or City C.

The second question relates to customer search behavior, the motivated decision to seek new inputs [13], one step of their total buying process (e.g., looking for advertising information, visiting stores). If geo-demographic differences exist (vis-avis upscale versus downscale), then upscale residents might be more likely than downscale residents to display more active shopping behaviors. If the latter have less 
tendency to engage in active shopping behavior they would be less likely to patronize the sponsor's store. Hypothesis 2 relates geo-demographics and buyer shopping behavior activity:

H2: The residents of City $A$ display more active shopping behaviors than residents of City B or City C.

Question three focuses on shoppers' expectations of women's clothing stores. This issue concerns whether upscale shoppers have higher demands and expectations than downscale shoppers, a difference indicating upscale shoppers consider, for example, merchandise selection or ease of returns, important when deciding which stores to visit. Hypothesis 3 looks at geo-demographics and shopper expectations:

H3: Residents of City A have higher expectations of women's clothing stores than do residents of City B or City C.

Fourth, are shoppers' evaluations of the sponsor's store. High evaluations would be expected from upscale residents, given the type of store and merchandise presented. The implication is that because upscale residents seek a store like what the sponsor offers, they would give higher evaluations; downscale residents, making fewer visits, would give lower evaluations. Hypothesis 4 relates geo-demographics and evaluations of the sponsor's store:

H4: Residents of City A hold higher evaluations of the sponsor's store than do residents of City B or City C.

Overall, if the predicted differences exist between City A and City B (or City A and City $C$ ), then distinct market segments would be concluded to exist. Finding this result might explain why sales had declined to low levels: there was not a sufficient target customer base to support this store.

\section{Research Methodology}

The sponsor requested several conditions be fulfilled when conducting this project. Specifically, these were:

1) Questions and response categories used in a previous study were to be followed as closely as possible. The sponsor was familiar with these questions which would allow for comparisons to be made between this study and the earlier study.

2) Mall-intercept interviewing would ease the survey execution, save costs, and speed the timing for conducting the study. This convenience sampling method was utilized. 
3) A total of 119 interviews were conducted. Of this total, 22 were from City A (18\%) and 23 from City B (19\%), cities specified by the sponsor as the main focus. A third area, City C, provided $49(\mathbf{4 1 \% )}$ interviews. It was comprised of three small cities plus a portion of the major city and had a fairly homogenous resident base, which was the rationale for grouping them into one unit. The three cities accounted for 94 (79\%) of the total interviews.

4) Survey respondents included day, night and weekend shoppers. Approximately onethird were sought from each period; the actual proportions were $29 \%, 29 \%$, and $42 \%$, respectively. Participants were to be over age eighteen and not employed at this center.

5) Interviewers selected participants by intercepting shoppers at three points along the outdoor causeway at this strip center. A total of 54 participants (45\%) indicated sufficient familiarity with the sponsor's store to provide an evaluation. Cities A, $B$, and $C$ accounted for 12,11 , and 21 , respectively (44 or $81 \%$ ), of the respondents evaluating the sponsor's store.

Survey questions covered four areas of inquiry: resident demographics, shopping behavior, evaluations of women's stores and evaluations of the sponsor's store. Shopping behavior questions were asked first, expectations of women's stores next, followed by evaluations of the sponsor's store, with demographic information asked last.

Both demographic and shopping behavior questions primarily utilized closed-end responses, asking participants to indicate the choice which best reflected their background or shopping behavior. The eight questions asking expectations of women's clothing stores employed a five point scale (1=low to $5=$ high). These questions were used for evaluating the sponsor's store.

A major problem using convenience sampling relates to its nonprobability method of selecting respondents. Convenience samples may provide good estimates but there is no objective method to determine if the sample is representative of the underlying population; even increasing the sample size will not make it more representative ([10], [16]).

Selection bias occurs because of the limitations of the mall intercept technique. Bias is due to: when and where in the mall the sample is selected; patronage habits (responding to special sales or weather conditions); frequency of visits to the center; and distance the respondent lives from the center which effects frequency of visitation ([17], [21]). When studying groups with particular characteristics (i.e., older households), bias can become very large. Weighting has been suggested as a method for correcting bias [21]. However, others have concluded weighting will not likely produce geographic representative data for ADIs, SMSAs or trade areas [17].

Because this project was for comparison purposes only, the sponsor was willing to accept the results of a nonprobability sample despite these shortcomings. Although trading-off cost and time savings for accuracy may be questioned by some, the sponsor believed the information gained for the cost incurred was worth the risk. 


\section{Evaluation of Results and Hypotheses}

Convenience sample selection raises the question of the appropriateness of parametric methods for statistical analysis. Parametric methods require two conditions to be satisfied: the population should be approximately normal and the observations be recorded on unambiguous measurement scales [5]. In this study it was suspected these conditions were not satisfied. Nonparametric statistical methods overcome both problems. They are favored for distribution-free populations, i.e., for categorical or ordinal scale items, and are appropriate for small and moderate size samples [5] as found in this study.

The demographic and shopping behavior profiles are found in Table 1 and Table 2 , respectively. The similarity or difference for each city's profile is analyzed using a paired comparisons sign test, an easy to use method requiring only the sign of the differences be determined. The null hypothesis:

$$
\text { H0: } P[+]=.5=P[-]
$$

is formulated against the statistic $S$, the number of successes in $n$ trials, based on the binomial distribution $b(n, .5)[5]$. Rejection for large values of $S$ would indicate the two groups are probably different.

\section{Hypothesis 1}

In Table 1, the demographic profiles for cities $\mathrm{A}, \mathrm{B}$, and $\mathrm{C}$ are compared. The residents of City A exceed City B on all six factors; nearly the same result was found comparing City A with City C residents with City A higher on five of the six factors (p< 0.02).

Table 1

Demographic Profiles

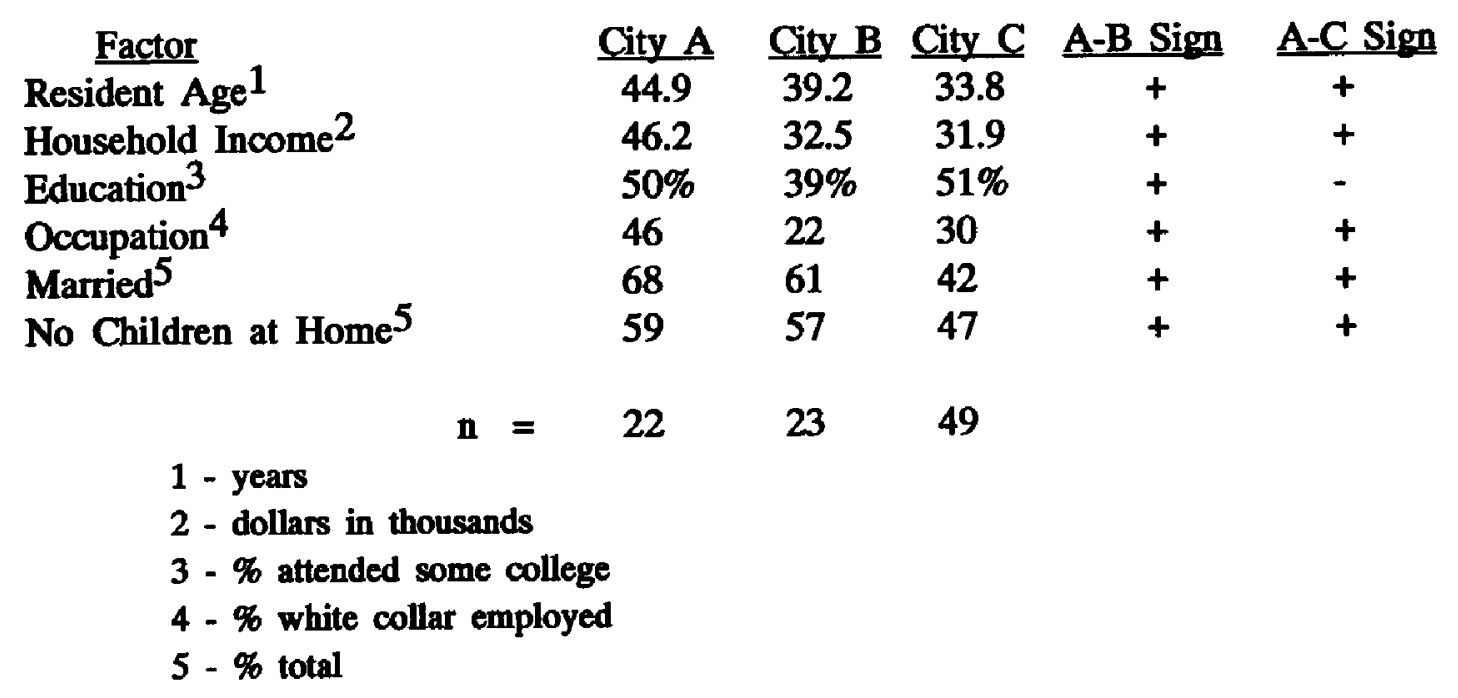


We note age, income level, and occupation as items supporting Hypothesis 1 that City $A$ residents are upscale compared to City $B$ or City $\mathbf{C}$ residents.

\section{Hypothesis 2}

Profiles of shopping behavior by city of residence are provided in Table 2 . Comparing City A residents versus City B, residents indicates seven items positive for City A with two positive for City B; this same result was found between City A and City C. Finding $S=7$ successes in $n=9$ items is significant at $p<0.05$ [5].

Table 2

Shopping Behavior Profiles

\begin{tabular}{|c|c|c|c|c|c|}
\hline Factor & City A & City B & City C & A-B Sign & A-C Sign \\
\hline Newspapers Read 1 & 1.68 & 1.52 & 1.47 & + & + \\
\hline Credit Cards Held 1 & 3.68 & 2.74 & 1.92 & + & + \\
\hline Trips to Center Per Month 1 & 5.85 & 5.17 & 4.39 & + & + \\
\hline Shop at Other Centers 1 & 1.68 & 1.43 & 1.59 & + & + \\
\hline Shop Any Women's Stores 1 & 3.50 & $\mathbf{3 . 3 0}$ & 4.82 & + & - \\
\hline Shop at Sponsor Store 2 & $55 \%$ & $17 \%$ & $14 \%$ & + & + \\
\hline Search Any Clothing Brands 2 & 32 & 35 & 24 & - & + \\
\hline Search Sponsor's Featured Brand 2 & 14 & 9 & 4 & + & + \\
\hline Median Spending Clothing/Year ${ }^{3}$ & 636 & 652 & 734 & - & - \\
\hline $\begin{array}{l}1 \text { - average number } \\
2 \text { - \% total } \\
3 \text { - dollars }\end{array}$ & 22 & 23 & 49 & & \\
\hline
\end{tabular}

The majority of evidence offers support for Hypothesis 2 that City $\mathbf{A}$ has more active shoppers than City B or City C.

Underlying this conclusion are several profile differences. First, there is the percent of City A versus City B or City $\mathbf{C}$ residents visiting the sponsor's store. Second, we note three minor differences: shop at other centers, trips to this center per month, and number of newspapers read.

For testing Hypotheses 3 and 4 regarding shoppers' views of women's clothing stores, Wilcoxson's Signed-Rank Statistic is employed. This statistic calculates the value $\mathrm{T}^{+}$by summing the ranks associated with the positive observations, then compares this value to the critical value $\mathbf{x}$ :

$$
\mathbf{P}\left[\mathbf{T}^{+} \geq \mathbf{x}\right]
$$

[5]. When $T^{+}$exceeds $x$, the two group are concluded to be significantly different. 


\section{Hypothesis 3}

The ratings attached to the eight items related to shoppers' expectations of the women's clothing stores are given in Table 3. Comparing City A to City B (one item was dropped because of a tie score) items rated higher for City A result in a total score of $25(p<0.04)$ [5]. However, comparing City A with City $C$, the latter has a higher ratings with a total score of $30(p<0.06)$.

\section{Table 3 \\ Expectations of Women's Stores}

\begin{tabular}{|c|c|c|c|c|c|c|c|}
\hline Factor & City A & City B & City C & Diff & tank & Diff & Rank \\
\hline Attractive Presentation & 4.00 & 4.00 & 4.28 & .00 & - & -.28 & 7 \\
\hline Convenient to Location & 4.55 & 4.22 & 4.53 & +.33 & 6 & +.02 & 2 \\
\hline Ease of Returns & 4.68 & 4.09 & 4.67 & +.59 & 7 & +.01 & 1 \\
\hline Fashion Appeal & 4.18 & 4.04 & 4.41 & +.14 & 4 & -.23 & 6 \\
\hline Merchandise Selection & 4.50 & 4.22 & 4.36 & +.28 & 5 & +.14 & 3 \\
\hline Personal Service Given & 3.82 & 3.91 & 4.16 & -.09 & 1 & -.34 & 8 \\
\hline Prices & 4.18 & 4.30 & 4.38 & -.12 & 2 & +.20 & 4 \\
\hline Speed at Counter & 4.09 & 3.96 & 4.31 & +.13 & 3 & -.22 & 5 \\
\hline $\mathbf{n}=$ & 22 & 23 & 49 & & & & \\
\hline
\end{tabular}

Hypothesis 3 is supported, that is City A residents have higher expectations of women's stores than City B residents. This hypothesis is not supported for City A versus City C; just the opposite is observed. One explanation for this result might be that City C residents magnify the differences between stores at this center compared to the stores near their place of residence to justify traveling the further distance to this center.

\section{Hypothesis 4}

Evaluations of the sponsor's store are presented in Table 4. Six of the eight items were rated higher by City A residents, two items rated higher by City B residents, producing a total score of $27(p<0.13)$ [5]. This same comparison for City A and City $C$ produced a total score of $28(p<0.10)$. 
Table 4

Evaluation of Sponsor's Store

\begin{tabular}{|c|c|c|c|c|c|c|c|}
\hline \multirow[b]{2}{*}{ Factor } & \multirow[b]{2}{*}{ City A } & \multirow[b]{2}{*}{ City B } & \multirow[b]{2}{*}{ City C } & \multicolumn{2}{|c|}{$\underline{\mathbf{A}-\mathbf{B}}$} & \multicolumn{2}{|c|}{$\mathrm{A}-\mathrm{C}$} \\
\hline & & & & $\underline{\text { Diff }}$ & Rank & Diff & $\underline{\text { Ranl }}$ \\
\hline Attractive Presentation & 4.33 & 3.91 & 4.06 & +.42 & 7 & +.27 & 7 \\
\hline Convenient to Location & 4.67 & 4.18 & 4.33 & +.49 & 8 & +.34 & 8 \\
\hline Ease of Returns & 4.25 & 3.91 & 4.00 & +.34 & 6 & +.25 & 6 \\
\hline Fashion Appeal & 4.17 & 4.09 & 4.22 & +.08 & 3 & -.05 & 2 \\
\hline Merchandise Selection & 3.67 & 3.63 & 3.88 & +.04 & 2 & -.21 & 5 \\
\hline Personal Service Given & 4.08 & 4.23 & 4.11 & -.15 & 4 & -.03 & 1 \\
\hline Prices & 3.67 & 3.64 & 3.61 & +.03 & 1 & +.06 & 3.5 \\
\hline Speed at Counter & 4.00 & 4.27 & 3.94 & -.27 & 6 & +.06 & 3. \\
\hline OVERALL & 4.00 & 3.91 & 4.17 & & & & \\
\hline $\mathbf{u}$ & 12 & 11 & 21 & & & & \\
\hline
\end{tabular}

The results indicate marginal support for Hypothesis 4 that City A residents have higher evaluations of the sponsor's store than City B. Comparing City A with City C, slightly greater support is evident.

\section{Overall}

Comparisons can be made based on the overall number of differences between the three cities. Based on the number of positive signs, City A had 24 of 30 items ( $p<0.01$ ) compared to City B. Compared to City $C$, the number of positive signs for City A number 21 of 31 items $(p<0.05)$. We conclude that City $A$ represents a unique market segment in this trading area distinct from either City B or City C.

\section{Conclusions and Managerial Implications}

We believe this study reemphasizes an important point for small business managers in the 1990s. Competitive pressures have increased the requirement for accurate and meaningful market information, making it an absolute prerequisite for survival and success. As shown in this study, a small retailer filling a market niche may require geo-demographic data about the trading area that is more than generalizations based on broad averages.

In the case of this small retailer, geo-demographic averages were used for describing the population in the area surrounding this shopping center, becoming an important input in the decision to open a new store. The logical assumption was that the overall averages would reflect the demographics of customers coming to this mall; this assumption later proved incorrect. In reality, the market averages distorted the presence of distinct customer segments: a smaller number of attractive target customers and a 
larger number of customers below the profile considered the store's clientele. This post hoc information led to the decision to close this store.

In our opinion, the challenge to "know your customer" has become an increasing and inescapable requirement, especially for small businesses. As observed from the above study, the need for detailed, accurate, and up-to-date information about customers is necessitated by the importance of the strategic decision being faced.

A solution to this information dilemma is offered. Cost can always be given as an objection to conducting any market research survey. We suggest, however, for the critical decisions that the dollars spent are relatively small and more efficiently used when compared to the costs of opening, operating, and closing an unprofitable store. If little or no up to date information about customers is readily available from the shopping center's management (the case in this study), agreeing to expand the study and share the costs between the center and retailer is a mutually beneficial alternative, one preferred to relying upon potentially outdated assumptions. Additionally, some financial and/or time constraints can be circumvented by asking for a few, basic geodemographic fundamentals: age, income level, occupation, city of residence, household composition, and frequency of visits to the center.

Finally, the above recommendation identifies an area where market research can provide management with help understanding the relationship between geo-demographics and customer behavior. This type of research should provide small business with surveys designed and tailored for answering key questions about their specific markets and improve their decision making capability.

\section{References}

1. Assel, Henry and Roscoe, Jr., A. Marvin. “Approaches To Market Segmentation Analysis," Journal of Marketing, Vol. 76 (1976), pp. 67-76.

2. Bass, Frank M., Tigert, Douglas J. and Lonsdale, Ronald T. "Market Segmentation: Group Versus Individual Behavior," Journal of Marketing Research, Vol. 5 (1968), pp. 264-70.

3. Beane, T.P. and Ennis, D.M. "Market Segmentation: A Review," European Journal of Marketing, Vol. 21 (1987), pp. $20-42$.

4. Berman, Barry and Evans, Joel R. Retail Management, 4th ed., New York, Macmillan Publishing Co., (1989), p. 234.

5. Bhattacharyya, Gouri $\mathbf{K}$ and Johnson, Richard A. Statistical Concepts And Methods, New York, John Wiley \& Sons, (1977), pp. 505-38, 588-94, 615-16.

6. Biggadike, E. Ralph. "The Contributions of Marketing to Strategic Management," Academy of Management Review, Vol. 6 (1981), pp. 621-32. 
7. Blattberg, Robert, Buesing, Thomas, Peacock, Peter and Sen, Subrata. "Identifying the Deal Prone Segment," Journal of Marketing Research, Vol. 15 (1978), pp. 369-77.

8. Cannon, Hugh M. and Linda, Gerald. "Beyond Media Imperatives: Geo-demographic Media Selection," Journal of Advertising Research, Vol. 22 (1982), pp. 31-36.

9. Cannon, Hugh M. and Rashid, Amir. "When Do Demographics Help in Media Planning?" Journal of Advertising Research, Vol. 30 (1991), pp. 20-26.

10. Churchill, Gilbert A. Marketing Research, 4th ed., New York, The Dryden Press (1987), pp. 217-18, 434-36.

11. Cravens, David A Strategic Marketing, 3rd ed., Homewood, IL, R.D. Irwin, Inc., (1991), pp. 162-95.

12. Dillon, William R., Madden, Thomas J. and Firtle, Neil H. Marketing Research In A Marketing Environment, 2nd ed., Homewood, I, R.D. Irwin, Inc., (1990), pp. 288-89, 618-20.

13. Engel, James F., Blackwell, Roger D. and Kollat, David T. Consumer Behavior, 3rd ed., Hinsdale, IL, The Dryden Press, (1978), p. 238.

14. Kotler, Philip and Armstrong, Gary. Principles of Marketing, 4th ed., Englewood Cliffs, NJ, Prentice-Hall, Inc., (1989), p. 226.

15. Mason, J. Barry and Ezell, Hazel F. Marketing Principles and Strategy, Plano, TX, Business Publications, Inc., (1987), p. 159.

16. McCarthy, E. Jerome and Perreault Jr., William D. Basic Marketing, 9th ed., Homewood, IL, R.D. Irwin, Inc., (1987), p. 81.

17. Murry Jr., John P., Lastorvicka, John L., and Bhalla, Gaurav. "Demographic and Lifestyle Selection Error in Mall-Intercept Data," Journal of Advertising Research, Vol. 29 (1989), pp. 46-52.

18. Peterson, Robert A. Marketing Research, 2nd ed., Plano, TX, Business Publications, Inc., (1988), pp. 308-9.

19. Riche, Maratha F. "New Frontiers For Geo-demographics," American Demopraphics, Vol. 12 (1990), p. 20.

20. Shelton, Dwight J. "Birds of a Geo-demographic Feather Flock Together," Marketing News Vol. 21 (1987), p. 13.

21. Sudman, Seymour. "Improving the Quality of Shopping Center Sampling," Journal of Marketing Research Vol. 17 (1980), pp. 423-31. 
22. Walsh, Doris. "Cluster Demographics Can Target Consumers But Zip-Code Groupings May Not Be Aocurate," Marketing News, Vol. 17 (1983), pp. 24-25.

23. Warren, William E., Stevens, Robert E., and McConkey, William. "Using Demographic and Lifestyle Analysis to Segment Individual Investors," Financial Analyst Joumal, Vol. 46 (1990), pp. 74-77.

24. Wind, Yoram. "Issues And Advances In Segmentation Research," Journal of Marketing Research, Vol. 15 (1978), pp. 317-37.

25. Winter, Frederick W. "Match Target Markets To Media Audiences," Journal of Advertising Research, Vol. 20 (1980), pp. 61-66.

25. Zeithaml, Valarie. "Piecing Together A Fragmented Market," Marketing and Media Decisions, Vol. 21 (1986), p. 160. 